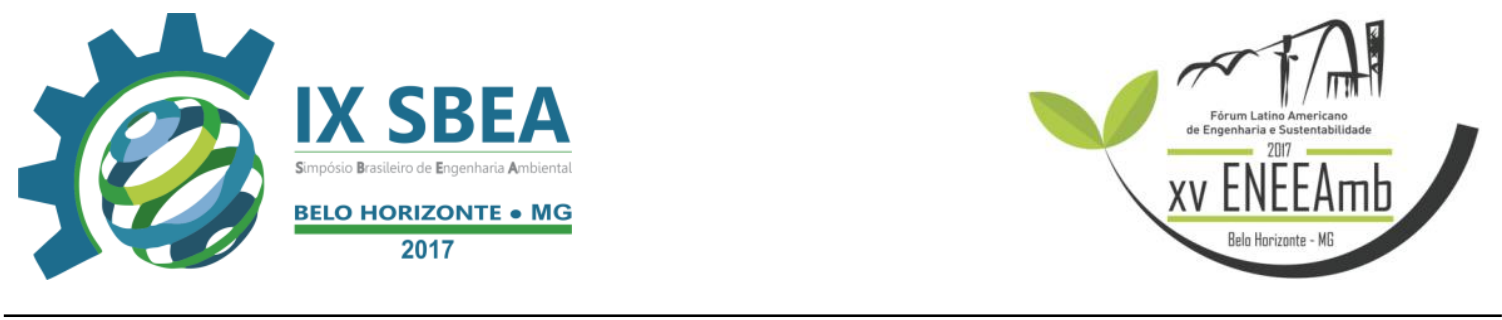

\title{
A FORMA RUDIMENTAR DA COLETA E ARMAZENAMENTO DOS RESÍDUOS SÓLIDOS NO NORTE DO BRASIL
}

\author{
Ana Luiza Costa Dias - analuizadias1@gmail.com \\ Universidade de Santo Amaro- UNISA/ Instituto Federal do Pará - IFPa \\ Caroline Araújo Buna - carol.bunna@gmail.com \\ Universidade de Santo Amaro- UNISA/ Univerdidade Federal do Pará - UFPa
}

\section{RESUMO}

Inúmeras são as consequências danosas ocasionadas pela coleta inadequada e decomposição desordenada dos resíduos sólidos no norte do país, isso afeta a população no nível ambiental, social e público, sabe-se que grande parte dos problemas ambientais existentes no norte esta relacionado à falta de infraestrutura, assim como os problemas de ordem social estão relacionados à educação precários proporcionados a população. Já no âmbito público os problemas são direcionados ao saneamento básico, moradia e saúde. A destinação final do lixo no norte é o aterro controlado, o sistema de coleta nas ruas é simples, a coleta é realizada por empresas terceirizadas, um ou duas vezes por semana com caminhão compressor, e depositado no aterro sanitário onde não recebe o cuidado necessário.

Palavras-chave: Resíduos sólidos, norte, aterro controlado, gestão ambiental. 


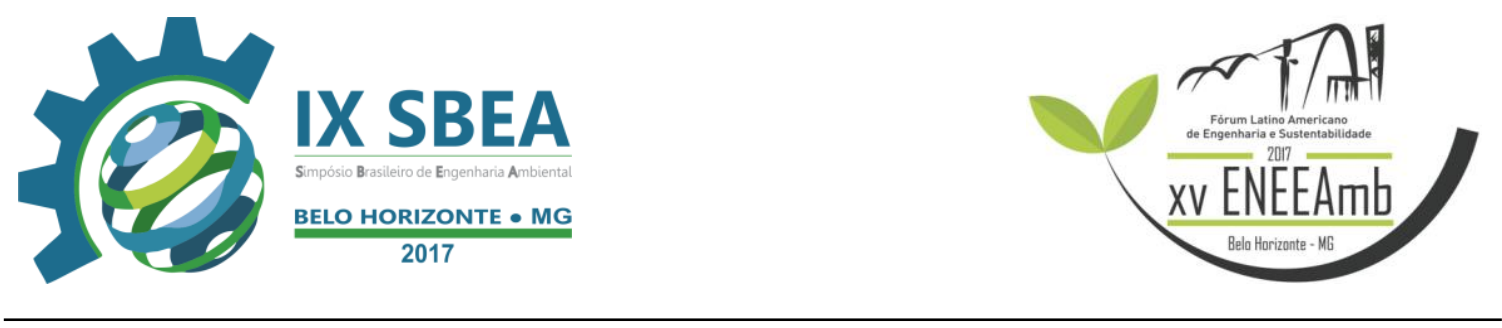

\section{OBJETIVO}

O artigo visa mostrar a realidade existente na deposição de resíduos, popularmente chamado de lixo e seus impactos ambientais, sociais e públicos. Visa também a criação de uma consciência ambiental de maneira didática.

\section{METODOLOGIA}

O norte é constituído por uma população com altos desníveis sociais, devido a isso os problemas educacionais voltados ao meio ambiente agravam-se, já que os trabalhos governamentais não são o suficiente para atender os problemas de toda a população, à vista disso, a deposição de resíduos é executada de forma rudimentar.

Segundo informações de Edmilson Silva, Belém do Pará produz cerca de 1800 toneladas de lixo diário, a disposição desordenada desses resíduos acarreta numa grande massa diária de dejetos cuja coleta é feita de forma inadequada, pois o serviço é realizado por empresas terceirizadas, onde é feita a utilização do compactador que condensa até $250-300 \mathrm{~kg}$ originais em $50-100 \mathrm{~kg}$ originais e essa compressão gera problemas como:

\subsubsection{Desperdício de recursos naturais.}

O problema de esgotamento de recursos naturais esta entrelaçados com a cultura de consumo.

"Os mais sérios problemas globais de desenvolvimento e meio ambiente que o mundo enfrenta decorrem de uma ordem econômica mundial caracterizada pela produção e consumo sempre crescentes, o que esgota e contamina nossos recursos naturais, além de criar e perpetuar desigualdades gritantes entre as nações, bem como dentro delas. Não mais podemos tolerar tal situação, que nos levou além dos limites da capacidade de sustento da Terra, e na qual vinte por cento das pessoas consomem oitenta por cento dos recursos mundiais. (....) Devemos lutar para equilibrar a sustentabilidade ecológica equitativamente, entre os países e dentro dos mesmos. (....) O sistema econômico deve ser estruturado à parte da produção e consumo de bens supérfluos para minorias, para concentrar-se na produção de bens que atendam às necessidades humanas básicas para todas as pessoas. O consumo e produção globais devem ser freados para se ajustarem à capacidade de recuperação da Terra. A redução do consumo deve ter prioridade sobre a reutilização e reciclagem de produtos. (...) Enquanto a pobreza tem como resultado 


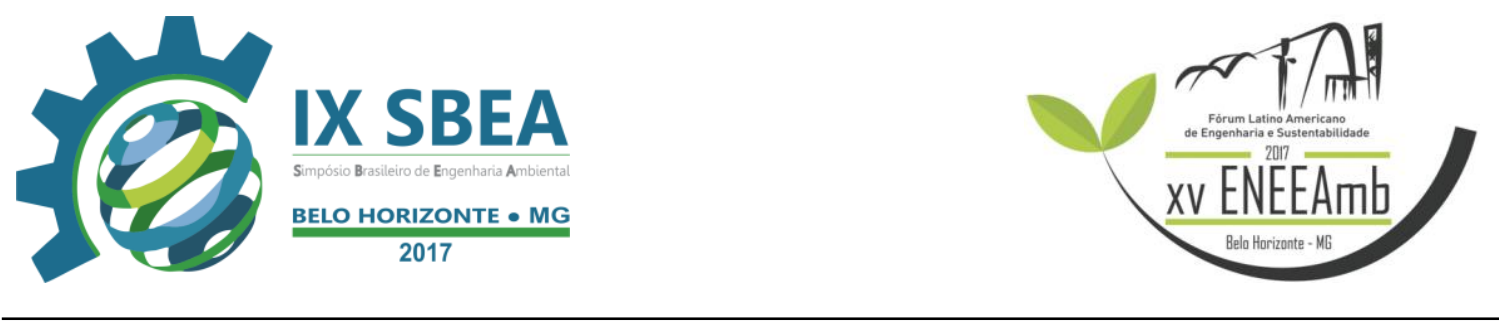

determinados tipos de pressão ambiental, as principais causas da deterioração ininterrupta do meio ambiente mundial são os padrões insustentáveis de consumo e produção, especialmente nos países industrializados. Motivo de séria preocupação, tais padrões de consumo e produção provocam o agravamento da pobreza e dos desequilíbrios. É preciso adotar medidas que atendam aos seguintes objetivos amplos: (a) promover padrões de consumo e produção que reduzam as pressões ambientais e atendam às necessidades básicas da humanidade; (b) desenvolver uma melhor compreensão do papel do consumo e da forma de se programar padrões de consumo mais sustentáveis" (Nações Unidas, 1997, p.39-40 e Fórum Global, 1992, apude, PORTILHO, 2003)." Recursos naturais são utilizados apenas uma vez e logo é desperdiçado, presumidamente para sempre uma vez que, ao ser compactado, a matéria prima se torna inutilizável.

\subsubsection{Custos altos.}

Mais de $50 \%$ dos municípios brasileiros não cobram pelo serviço de limpeza urbana, (IBGE 2002) dispondo de outras fontes de recursos do orçamento municipal para realização do trabalho necessário, são gastos aproximadamente $\mathrm{R} \$: 18$ mil mensal por caminhão. De acordo com o orçamento estimativo para cidade de 100,000 habitantes, são gastos mensalmente $\mathrm{R}$ \$5,596,00 a cada 120 ton/m de resíduos sólidos em coleta e transporte de regular.

\subsubsection{Poluição visual.}

As latas de lixo danificam a beleza urbana da cidade visto que, poluição visual "gera desarmonia ou desequilíbrio no meio ambiente artificial [...], prejudicando o bem estar da população, comprometendo a saúde das pessoas, através de efeitos psicológicos difíceis de serem diagnosticados, enquadrando-se no conceito jurídico de poluição (art. $3^{\circ}$, III, da Lei n. 6.938/81)". Há também a degradação do meio, pois "é fruto da violação estética de um padrão paisagístico médio a ser aferido em cada caso, seja afetando uma paisagem naturalmente bela, ou portadora de outro predicado relevante, ou alterando uma paisagem urbana de maneira desarmônica e agressiva" (CASTANHEIRO, 2009).

\subsubsection{Poluição sonora.}

Depois da poluição da agua e do ar, a poluição sonora é o problema ambiental que afeta o maior numero de pessoa, o aumento do barulho urbano causado pelo congestionamento dos veículos utilizados na coleta de resíduos domiciliares é fonte de incomodo pra comunidade assim como paras os funcionários da coleta, Zannin (2002) 


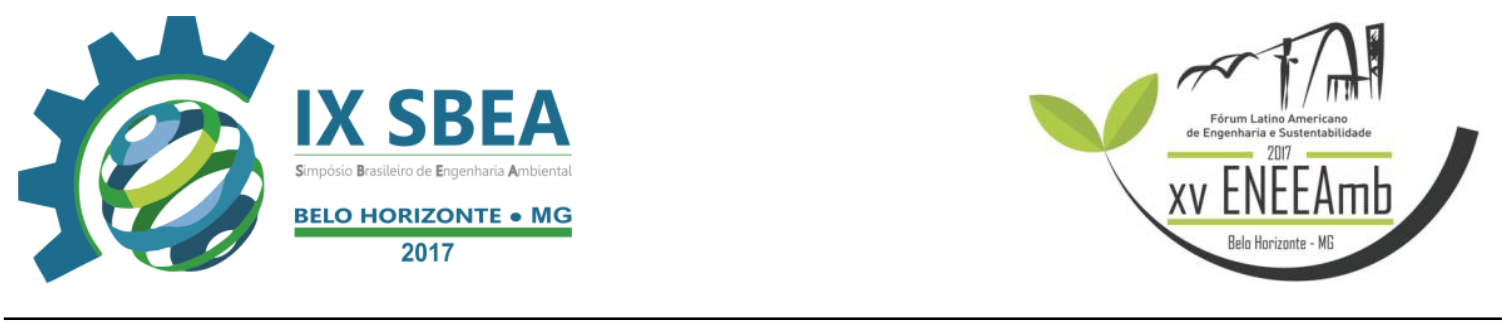

considera que o conhecimento adquirido nas pesquisas sobre ruídos não é o suficiente pra afirmar que há riscos a saúde, contudo os distúrbios duradouros causados pelos ruídos causam danos.

\subsubsection{Proliferação de roedores}

O acumulo de resíduos de forma inapropriada pode gerar a proliferação de pragas, ou seja, quando não recolhido no tempo apropriado ou se for recolhido pela metade o lixo contribui para a propagação de roedores propiciando riscos a saúde publica.

Os resíduos por fim chegam ao deposito, também chamado de "aterro controlado", essa deposição desordenada de dejetos causam inúmeras consequências nocivas, tanto no nível ambiental, quando na saúde pública e nível social. Além de disforme, os resíduos sólidos ocupam um valioso espaço, as latas de lixo ocupam calçadas, e há a desvalorização das propriedades vizinhas.

O solo é um recurso natural e como tal deve ser utilizada, contudo é um recurso finito, em virtude da deterioração dos resíduos sólidos, a camada superficial da crosta terrestre fica danificada já que a decomposição biológica da matéria orgânica, também conhecida como chorume, fica em contato direto com o solo e com o subsolo, além dos organismos patogênicos se proliferarem mais rápido no lixo. $\mathrm{O}$ não tratamento tem como consequência:

\subsubsection{A redução de fertilidade do solo}

O lixo urbano é constituído predominantemente por matéria orgânica e como tal sofre intensa decomposição, em contato com o solo, essa decomposição lesa a fertilidade, que é a capacidade do solo de conceder nutrientes, quando ocorre a lixiviação (água da chuva se infiltra no solo e dissolve substancias químicas, arrastandoas consigo) ocorre à perda de nutrientes, ou seja, o esgotamento do solo, isso acelera o processo de desertificação do mesmo.

3.2.2 A percolação do chorume no solo podendo atingir os lenções freáticos

A poluição da água é definida como a adição de materiais que podem modificar sua estrutura qualitativa, no aterro controlado, a falta de planejamento gera a 


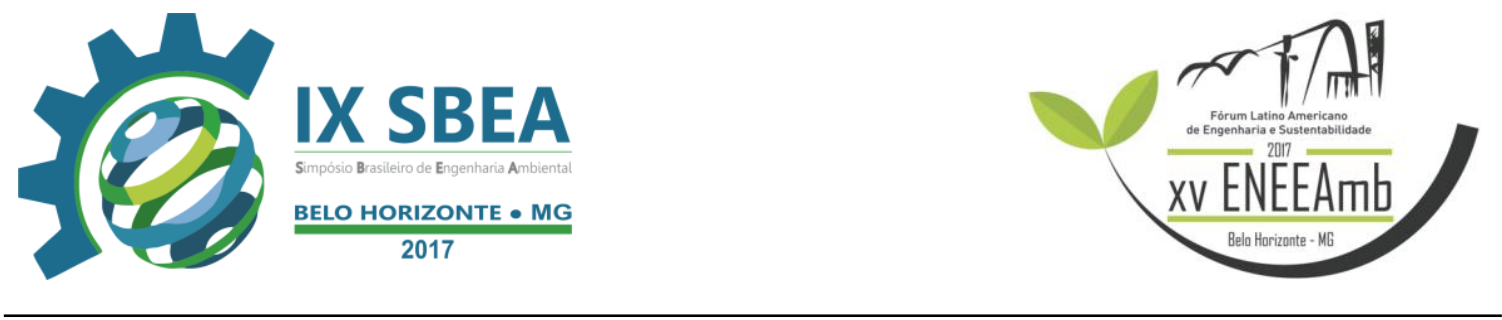

contaminação dos lençóis freáticos e aquíferos, pois, o chorume penetra no solo e contamina os arredores, como mostra a imagem abaixo.

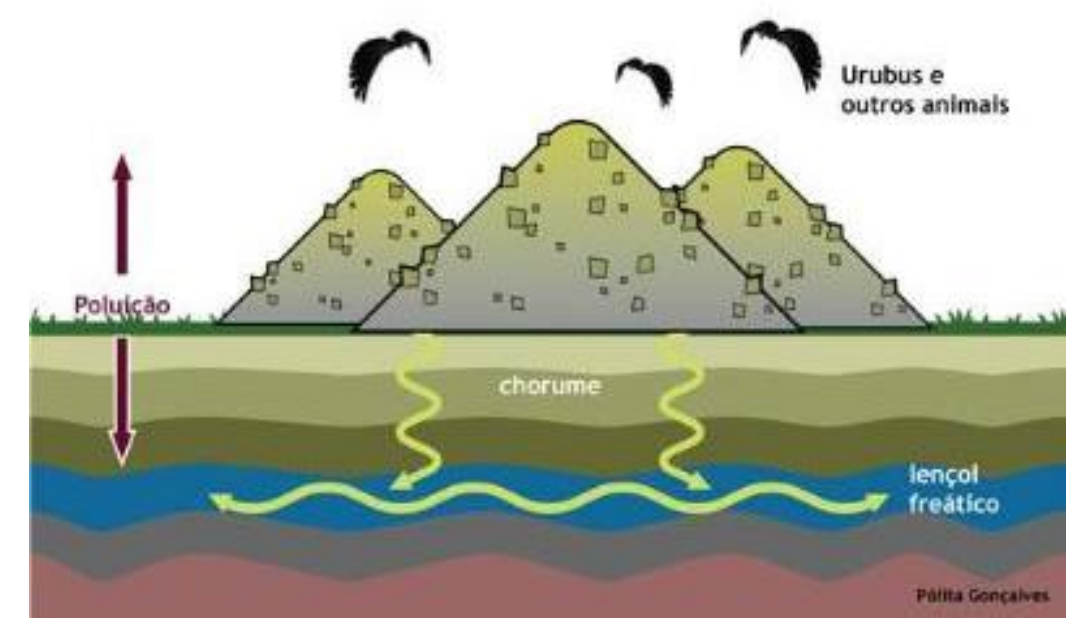

Figura 1: a forma rudimentar da coleta e armazenamento de resíduos sólidos.

3.2.3 Aumento de sua erodibilidade, desertificação e aumento de salinidade.

Na maioria dos casos, o chorume também contém produtos tóxicos, tais como mercúrio e chumbo, se o chorume for carregado pela chuva, ele pode contaminar o solo de forma que, se depositado de forma inadequada, o lixo não só causa poluição hídrica como também erosão e aumento de salinidade.

\subsubsection{Desequilíbrio ecológico}

Ao poluir os aquíferos e o solo, o aterro sanitário causa um desequilíbrio ecológico, há também a poluição do ar com a decomposição aeróbicas e anaeróbicas dos organismos decompositores existentes na matéria orgânica do lixo.

Todos esses malefícios ambientais trazem problemas diretamente relacionados à saúde publica, pois, o acumulo do lixo nas cidades e a falta de estrutura do aterro sanitário influencia diretamente na proliferação de doenças epidemiológicas na comunidade. Os resíduos urbanos causam uma preocupação pelo descontrole extenso de sua produção, a disposição final inadequada é um fator de risco à saúde, uma vez que a decomposição da matéria é atração de hospedeiros de macrovertores e microvetores. Os macrovetores são animais como, ratos, moscas, mosquitos, baratas, cães etc, já os 


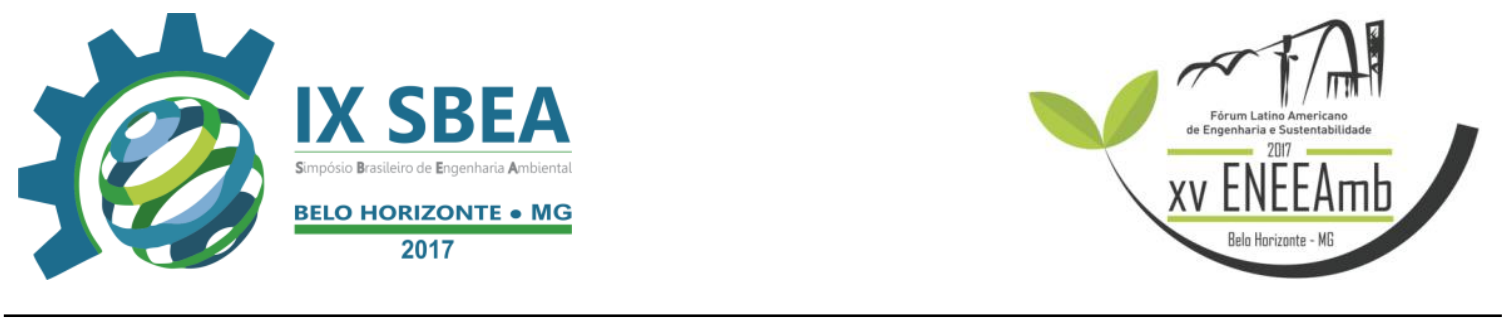

microvetores são bactérias, fungos, vírus, vermes. Esses vetores transmitem doenças como febre amarela, dengue, malária, elefantíase, leptospirose, etc.

Pode haver também a contaminação por chorume no abastecimento de água da região, ocasionando doenças como micose, diarreia e vomito, assim como a contaminação dos rios e lagos que contamina os peixes e algas, portanto, a coleta e o aterro sanitário, se não tratado de forma inadequada, constitui grave ameaça à saúde pública.

Dentre as possíveis soluções para a resolução dos problemas provenientes ao aterro sanitário e a coleta do lixo, esta promover por meio de projetos governamentais, a educação à população, e que através do processo educativo, fosse criado consciência crítica, campanhas de educação ambiental podem conscientizar a população sobre a necessidade de conservação da natureza. Como visto no art.225 1º, VI, da Lei no 8974, "promover a educação ambiental em todos os níveis de ensino e a conscientização pública para a preservação do meio ambiente", ou seja, a educação ambiental deve ser vista como forma consciência ecológica para a sociedade. Outra possibilidade é elaboração de um plano de investimento no setor de saneamento básico, de forma que o aterro sanitário fosse refeito em perfeitas condições para receber os resíduos sólidos de maneira que não prejudicasse o meio ambiente, assim como planos de tratamento de água para transformar a água do esgoto em adubo, tal como projetos de compostagem, reciclagem e separação seletiva do lixo. Tal como visto no modelo abaixo.

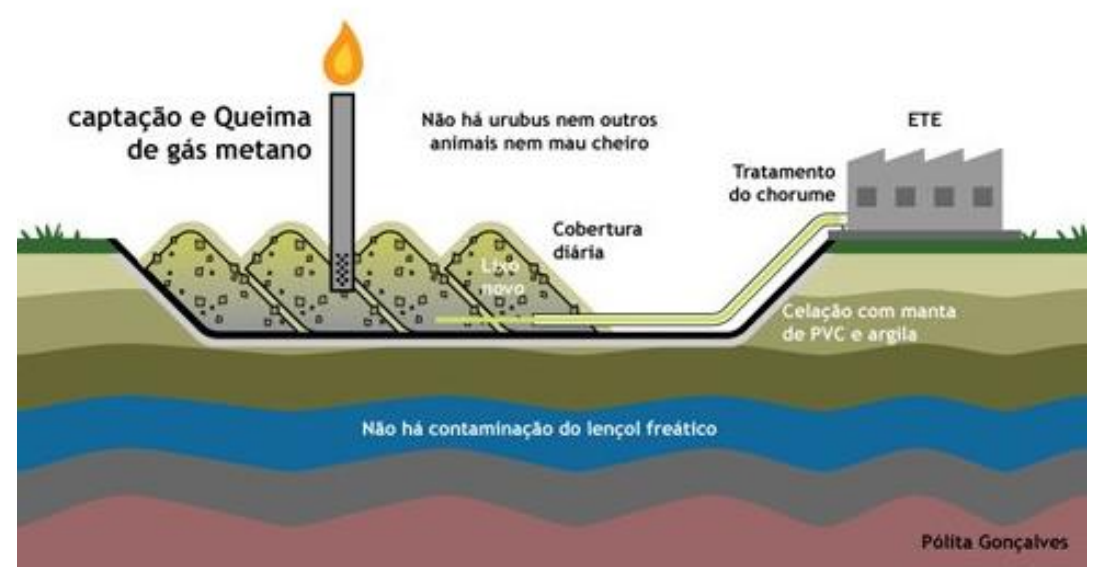

Figura 2: a forma rudimentar da coleta e armazenamento de resíduos sólidos, modelo de aterro sanitário. 


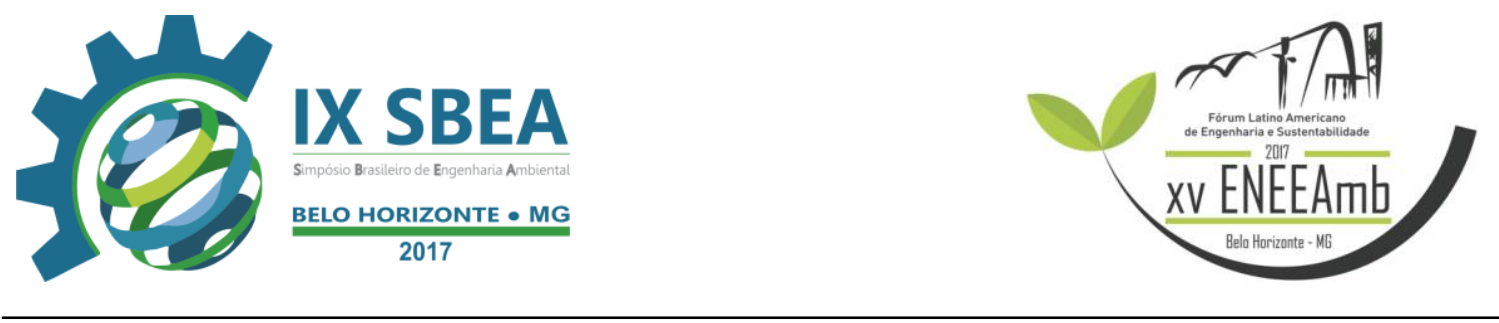

Outra possibilidade seria a não redução de resíduos sólidos, através da retenção de gasto material e aumento a vida útil de um produto. Segundo Fiolorillo Rodrigues, fixa a ideia de consciência ecológica "é procurar sempre utilizar tecnologia limpa, incentivar à realização da solidariedade, já que o meio ambiente é uno e indivisível, devendo ser acessível a todos, para perfeito funcionamento do principio da participação". 


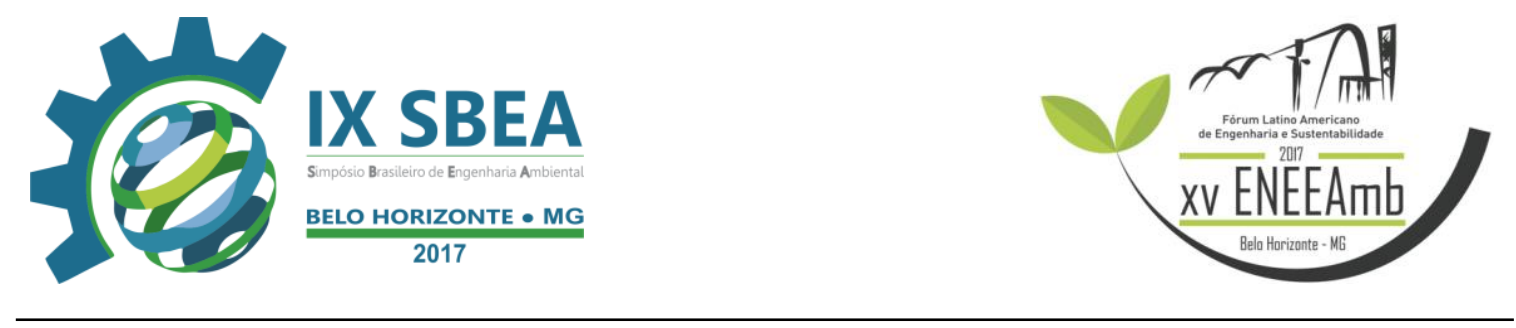

\section{REFERÊNCIAS BIBLIOGRÁFICAS}

NAÇÕES Unidas, 1997, p.39-40 e Fórum Global, 1992, apude, PORTILHO, 2003. Disponível em: http://www.conteudojuridico.com.br/pdf/cj035864.pdf. Acesso em: 27 maio, 2017.

CONSTUIÇÃO federal, 225 1ํ, VI, da Lei no 8974/5, 1995. Di225 1으, VI, da Lei no 8974,ponivel em

http://alerjln1.alerj.rj.gov.br/constfed.nsf/16adba33b2e5149e032568f60071600f/62e3ee 4d23ca92ca0325656200708dde?OpenDocument. Acesso em 30 maio, 2017.

PRESIDÊNCIA da republica, art. 3º, III, da Lei n. 6.938/81, 1990. Disponível em: http://www.planalto.gov.br/ccivil_03/leis/L6938.htm. Acesso em 28 maio, 2017.

CASTANHEIRO, Ivan Carneiro. A Poluição Visual: Formas de Enfrentamento pelas

Cidades. Revista Internacional de Direito e Cidadania, n. 4, p. 63-78, junho,2009.

LIMA, J. D. Gestão de Resíduos Sólidos no Brasil. João Pessoa, PB, 2003.

ZANNIN P.H.T., CALIXTO A., DINIZ F. B. D., FERREIRA J. A. C., SCHULLER R. Incômodo Causado pelo Ruído Urbano à População de Curitiba, PR. Revista de Saúde Pública, São Paulo, v.36, n. 4, p. 521-524, 2002.

FIORILLO, Rodrigues. Op. Cit. P 147.

SEWELL, H.Granville. Adiministração e controle da qualidade ambiental, p. 304$315,1978$.

MORAIS, Raimundo; BENATTI, José; MAUÉS, Antonio. Direito ambiental e políticas públicas na Amazônia, p. 231-239, 2007. 